\title{
Impact of Gender Difference on Characteristics and Outcome of Chronic Hepatitis C
}

\author{
Mahmoud Saif-Al-Islam', Hamdy Saad Mohamed ${ }^{2}$, Mustafa Adel Younis ${ }^{3}$, \\ Mahmoud Yosef Abdelhamid ${ }^{4}$, Magda Mohamed Ali ${ }^{5}$, Safaa Khalaf ${ }^{1}$ \\ ${ }^{1}$ Departments of Tropical Medicine and Gastroenterology, Sohag University Hospital, Sohag, Egypt \\ ${ }^{2}$ Departments of Internal Medicine, Sohag University Hospital, Sohag, Egypt \\ ${ }^{3}$ Departments of Clinical Pathology, Sohag University Hospital, Sohag, Egypt \\ ${ }^{4}$ Departments of Radiology, Sohag University Hospital, Sohag, Egypt \\ ${ }^{5}$ Departments of Community Medicine, Sohag University Hospital, Sohag, Egypt \\ Email:mahmoud_elislam@med.sohag.edu.eg
}

How to cite this paper: Saif-Al-Islam, M., Mohamed, H.S., Younis, M.A., Abdelhamid, M.Y., Ali, M.M. and Khalaf, S. (2020) Impact of Gender Difference on Characteristics and Outcome of Chronic Hepatitis C. Open Journal of Gastroenterology, 10, 281-294.

https://doi.org/10.4236/ojgas.2020.1011027

Received: August 29, 2020

Accepted: November 2, 2020

Published: November 5, 2020

Copyright (c) 2020 by author(s) and Scientific Research Publishing Inc. This work is licensed under the Creative Commons Attribution International License (CC BY 4.0).

http://creativecommons.org/licenses/by/4.0/

\begin{abstract}
Gender difference in chronic hepatitis C (CHC) infection is not previously well studied. We aimed to analyze the effect of gender difference on the risk factors of $\mathrm{CHC}$, disease progression, and outcome after oral direct acting antiviral (DAA) therapy. The study was conducted at Tropical Medicine and Gastroenterology Department, Sohag University, Egypt, in the period between 2018 and 2020. 775 patients were evaluated for hepatitis C virus (HCV) risk factors. Laboratory investigations, abdominal ultrasound and liver Shear wave elastography (SWE) were done. The patients were given antiviral therapy and followed up to assess the response and side effects of DAA therapy. 434 (56\%) of study patients were males and 341 (44\%) were females. Catching infection from blood transfusion and intravenous (IV) injection of tarter emetic was significantly higher in males, while catching infection from surgical operation was significantly higher in females. Hepatic fibrosis was significantly more extensive in males. Side effects were reported more in females. Sustained virological response (SVR) 12 was reported in 98.6\%. Females had a slightly better SVR12 than males (99.4\% versus $97.9 \%)$. In conclusion males were different from females in exposure to HCV risk factors. After introduction of blood screening and stoppage of parenteral anti-bilharzial therapy the risk of HCV infection could be greatly prevented in males, while the exposure of females to obstetric procedure is increasing nowadays which hides a risk of ongoing infection in females. So, HCV surveillance programs in females retain their importance in early detection and management of CHC. Although hepatic fibrosis progression was more in males, females were more liable to adverse events of DAA therapy. So, researchers should consider the gender of their patients in drug design and administration.
\end{abstract}




\section{Keywords}

Chronic HCV, Risk Factors, Gender Difference, DAA Therapy

\section{Introduction}

Hepatitis C virus infection is a global health problem. The prevalence rate of HCV infection in 2015 was $1 \%$ worldwide [1]. Egypt has the highest prevalence rate of HCV in the world [2]. The national seroprevalence of HCV in 2008 was $14.7 \%$ in people aged 15 - 59 years and was higher in males than in females [3]. This seroprevalence decreased in 2015 to 6.3\%. This decrease in the prevalence may be due to the significant decrease in HCV new infections; also the group of patients who received parenteral anti-bilharzial therapy in the 1950s and 1960s, that had the highest prevalence, had been aged much [4].

Parenteral anti-bilharzial therapy and blood transfusion were associated with HCV infection in Egypt. Nowadays, parenteral anti-bilharzial therapy is obsolete [5], and the risk of transmission through blood transfusion is greatly declined with the application of blood screening technology [6] [7].

The recent development of highly efficacious oral DAA therapy provides opportunities for reducing the burden of chronic liver disease (CLD) related to HCV infection [8]. Gender difference affects HCV progression and outcome; for instance, clearance of HCV infection in females is higher than males [9]. Females had a decreased rate of decompensated cirrhosis, and less commonly have malignant liver tumors [10]. CHC progression is known to be worse in males [11]. Also, males had 2 folds more risk to die from CLD than females [10]. The aim of this work is to analyze the effect of gender difference on risk factors of $\mathrm{CHC}$, disease progression and outcome after oral DAA therapy.

\section{Patients and Methods}

This is a prospective cohort study conducted at Tropical Medicine and Gastroenterology Department, Sohag University hospitals, Egypt, on patients with $\mathrm{CHC}$ who are candidate for sofosbuvir-based antiviral therapy between 2018 and 2020. According to the standards of the Local Ethical Committee, written informed consents were obtained from all participants. The exclusion criteria were age below 18 years, HCV and hepatitis B virus co infection, other causes of CLDs, advanced liver disease and patients with chronic kidney disease. The patients were subjected to:

- Detailed history taking for assessment of the risk factors of HCV infection.

- Ten milliliters of blood were drawn from each patient; $1.8 \mathrm{ml}$ in Plastic Citrated tube (9NC sodium citrate vacutainer, $3.2 \%) 2 \mathrm{ml}$ in an $\mathrm{K}_{3}$-EDTA vacutainer for Complete blood count (CBC), $3 \mathrm{ml}$ in lithium heparin vacutainer for liver function tests, and the rest in gel vacutainer for serology and quantitative polymerase chain reaction (PCR). Vacutainers were (BD); (Becton Dick- 
inson Systems, San Jose, CA, USA).

- Serology: HCV antibody was carried out using the Architect ${ }^{\circledR}$ i2000SR anti-HCV (CIA) chemiluminescence system (Abbott Laboratories, Diagnostics Division, Abbot Park, IL, USA).

- Quantitative HCV RNA level by Real-time PCR using QIAcube system (Qiagen, Hilden, Germany) with Spin tubes protocols (Qiagen) and The StepOne ${ }^{\mathrm{mm}}$ Real-Time PCR System (Applied Biosystems, Life Technologies, Foster City, CA, USA).

- Abdominal ultrasounds and liver real-time Shear wave elastography (SWE) using (Toshiba Aplio 500) done for the study purpose at Radiology Department, Sohag University Hospital. All cases were done by a single operator, with placing the patient in a supine position, the right arm is in a maximum abduction to widen the intercostal spaces, and to acquire a stable image the patient asked to hold his breath in the expiration, then the convex probe placed in the intercostal spaces. The SWE box placed $2 \mathrm{~cm}$ sub-capsular in a uniform zone to avoid reverberation artifacts. Also, the operator avoided the perivascular areas as they may alter the estimations of liver stiffness. The color map is used but it is not dependable to assess liver stiffness because it is not quantitative. We mainly depended on liver stiffness measurement in $\mathrm{m} / \mathrm{s}$. For each patient the elastography acquisition was repeated five times. Freeze of real-time SWE 2D color map of the stiffness (in $\mathrm{m} / \mathrm{s}$ ) after a stabilization of at least $3 \mathrm{~s}$ for each acquisition was done. SWE color box size was about 4 $\times 4 \mathrm{~cm}$. The measurements were performed in a 2 to $3 \mathrm{~cm}$ diameter region of interest (ROI). For each patient, liver stiffness was considered as the median of multiple SWE successful measurements (Figure 1).

The patients were given Sofosbuvir-based antiviral therapy, for 12 weeks duration, according to the modified protocol of Egyptian national program for treatment of HCV (Figure 2).

Patients' follow up was done in Tropical Medicine and Gastroenterology outpatient clinic every 4 weeks until the end of therapy, and then at 12 weeks thereafter. CBC and liver function tests were repeatedly assessed every 4 weeks. All patients were assessed for the possible side effects of DAA therapy as headache, fatigue, GIT upset, diarrhea and dyspnea. Patients who were negative for serum

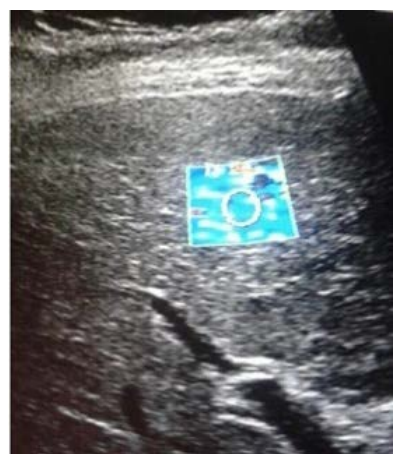

Figure 1. SWE measurement of liver in cirrhotic patient. 


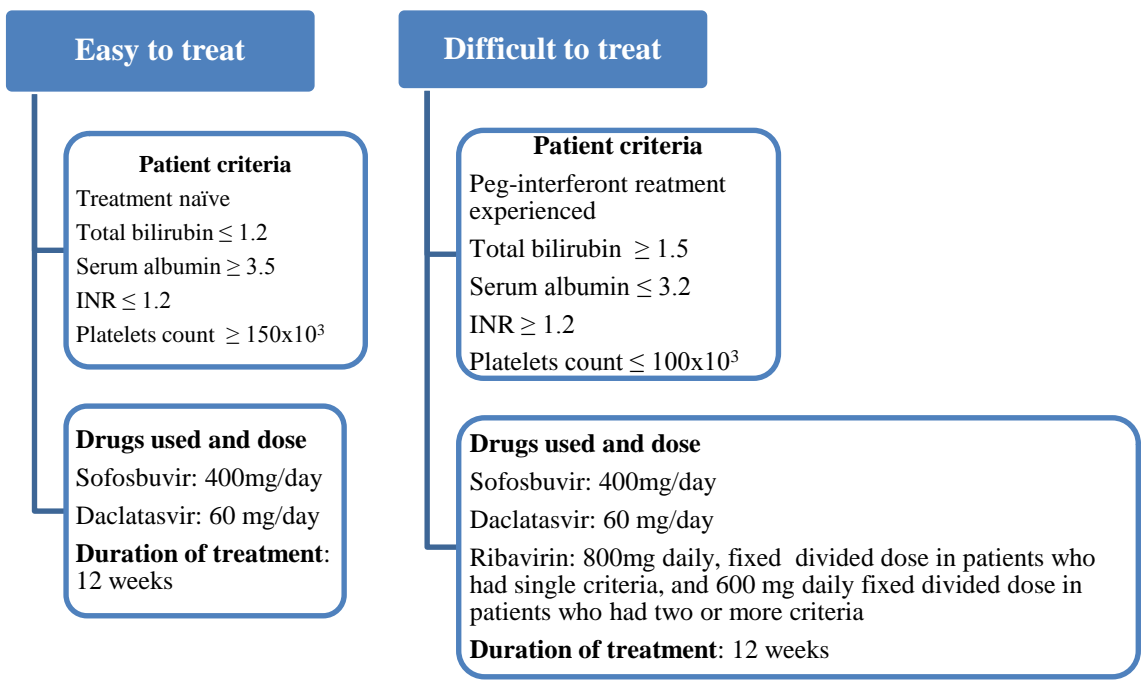

Figure 2. Flowchart for the modified national program for treatment of HCV in Egypt provided by National Committee for Control of Viral Hepatitis.

HCV RNA at the EOT and 12 weeks thereafter were defined as responders achieving SVR12. A positive HCV RNA 12 weeks after end of treatment (EOT) was defined as relapse [12].

\section{Statistical Analysis}

Data were analyzed using SPSS version 16. Quantitative data were represented as mean \pm standard deviation, median and interquartile range (IQR). The data were tested for normality using Shapiro-Wilk test. Students'-T-test was used for normally distributed data while Mann-Whitney test was used when the data were not normally distributed. Paired data were compared by Wilcoxon rank test. Qualitative data were presented as number and percentage. Comparison of data was done by Chi-square test and Fischer Exact test when suitable. Interaction between gender, stage of hepatic fibrosis and age was tested by two-way ANOVA and the interaction plots were obtained. Logistic regression was used to analyze variables which had a statistical impact on SVR. Graphs were produced by SPSS program. $\mathrm{p}$ value $<0.05$ was considered significant.

\section{Results}

Seven hundred seventy-five patients with CHC were included in the study, 434 (56\%) were males and 341 (44\%) were females.

\section{Gender difference regarding exposure to $\mathrm{HCV}$ risk factors:}

The most frequent risk factors of HCV infection were previous history of hospital admission, blood transfusion and exposure to needle stick. In males the most common risk factors were blood transfusion (28.6\%), hospital admission (24.7\%) and IV injection of tarter emetic (18.7\%). In females the most common risk factors were hospital admission (26.7\%), exposure to needle stick (18.2\%) and previous operation (17.3\%). The risk of infection from blood transfusion 
and IV injection of tarter emetic were significantly higher in males $(\mathrm{p}<0.001)$, while the risk of infection from surgical operation was significantly higher in females $(\mathrm{p}=0.007)($ Table 1$)$.

\section{Gender and baseline laboratory characteristics in $\mathrm{CHC}$ patients:}

In patients with $\mathrm{CHC}$ the mean age was closely comparable between the two gender groups. Males had significantly higher hemoglobin, albumin, prothrombin time and bilirubin levels but significantly lower platelets count compared to females (Table 2).

\section{Gender distribution in different stages of hepatic fibrosis:}

Hepatic fibrosis measured by SWE was significantly more extensive in males than in females $\left(\chi^{2}=10.20, p=0.037\right)$ (Table 2$)$. There was a significant difference in hepatic fibrosis stages in males compared to females when considering the patients' age $(\mathrm{p}=0.016)$. The mean ages of males with different stages of hepatic fibrosis (F0-F3) were closely related, while in females advanced fibrosis (F3) was present in old age. F4 was positively correlated with old age in both gender groups and females with F4 were older than males with F4 stage ( $\mathrm{p}<$ 0.001) (Figure 3).

Hematological and biochemical changes after sofosbuvir-based antiviral therapy:

At EOT there were highly significant increase in white blood cells (WBCs) count, platelets count, and total bilirubin level $(\mathrm{p}=0.003, \mathrm{p}=0.015, \mathrm{p}<0.001$ respectively), and there were a highly significant decrease in hemoglobin ( $\mathrm{p}=$ 0.019), albumin, alanine aminotransferase (ALT) and aspartate aminotransferase (AST) levels $(\mathrm{p}<0.001)$ compared to the baseline laboratory data. The increase in platelets count was significantly more in males $(p=0.049)$, while the increase in total bilirubin level and decrease in albumin level significantly more in females ( $\mathrm{p}=0.001, \mathrm{p}<0.001$ respectively) (Table 3 ).

\section{Side effects of DAA therapy:}

Fatigue was the most frequent reported side effect (42\%) followed by headache (24\%), gastrointestinal tract (GIT) upset (16\%) and few cases of mild anemia (3\%). Side effects were reported more in females. Fatigue and GIT upset were significantly higher in females (Table 4).

Table 1. Gender difference regarding exposure to HCV risk factors.

\begin{tabular}{ccccc}
\hline Risk factors & $\begin{array}{c}\text { Total } \\
\mathbf{n}=\mathbf{7 7 5}\end{array}$ & $\begin{array}{c}\text { Males with CHC } \\
\mathbf{n}=\mathbf{4 3 4}\end{array}$ & $\begin{array}{c}\text { Females with CHC } \\
\mathbf{n}=\mathbf{3 4 1}\end{array}$ & p value \\
\hline Hospital admission & $198(25.5 \%)$ & $107(24.7 \%)$ & $91(26.7 \%)$ & 0.52 \\
Blood transfusion & $171(22 \%)$ & $124(28.6 \%)$ & $47(13.8 \%)$ & $\mathbf{0 . 0 0 0}$ \\
Exposure to needle stick & $131(17 \%)$ & $69(15.9 \%)$ & $62(18.2 \%)$ & 0.413 \\
Operation & $105(13.5 \%)$ & $46(10.6 \%)$ & $59(17.3 \%)$ & $\mathbf{0 . 0 0 7}$ \\
Endoscopy & $101(13 \%)$ & $48(11.1 \%)$ & $53(15.5 \%)$ & 0.069 \\
IV injection of tarter emetic & $93(12 \%)$ & $81(18.7 \%)$ & $12(3.5 \%)$ & $\mathbf{0 . 0 0 0}$ \\
\hline
\end{tabular}

CHC: Chronic hepatitis C, N: Number. 
Table 2. Demographic, baseline laboratory characteristics and fibrosis staging in males compared to females in $\mathrm{CHC}$ patients.

\begin{tabular}{|c|c|c|c|}
\hline & Male patients with $\mathrm{HCV}$ & Female patients with $\mathrm{HCV}$ & $p$ value \\
\hline \multicolumn{4}{|l|}{ Age (years) } \\
\hline Mean \pm SD & $51.19 \pm 13.55$ & $51.17 \pm 14.29$ & 0.623 \\
\hline Median (IQR) & $56(49-62)$ & $55(41-62)$ & \\
\hline \multicolumn{4}{|l|}{ BMI } \\
\hline Mean \pm SD & $26.76 \pm 3.95$ & $28.61 \pm 4.07$ & 0.000 \\
\hline Median (IQR) & $24(26-28)$ & $25(28-31)$ & \\
\hline \multicolumn{4}{|l|}{ WBCs $\left(\times 10^{3} / \mathrm{mL}\right)$} \\
\hline Mean \pm SD & $6.64 \pm 2.34$ & $6.50 \pm 2.26$ & 0.401 \\
\hline Median (IQR) & $6.2(4.8-8.5)$ & $6.2(4.9-8)$ & \\
\hline \multicolumn{4}{|c|}{ Hemoglobin (g/dL) } \\
\hline Mean \pm SD & $15.03 \pm 1.44$ & $13.77 \pm 1.52$ & 0.000 \\
\hline Median (IQR) & $15.2(14.2-15.9)$ & $13.9(13-14.8)$ & \\
\hline \multicolumn{4}{|c|}{ Platelets count $\left(\times 10^{3} / \mathrm{mL}\right)$} \\
\hline Mean \pm SD & $213.68 \pm 67.89$ & $235 \pm 82.61$ & 0.000 \\
\hline Median (IQR) & $201(171-238)$ & $227(174-271)$ & \\
\hline \multicolumn{4}{|l|}{$\operatorname{ALT}(\mathrm{U} / \mathrm{L})$} \\
\hline Mean \pm SD & $53.77 \pm 37.86$ & $51.74 \pm 55.68$ & 0.385 \\
\hline Median (IQR) & $45(31-77)$ & $42(31-70)$ & \\
\hline \multicolumn{4}{|l|}{ AST (U/L) } \\
\hline Mean \pm SD & $54.96 \pm 37.06$ & $55.10 \pm 43.69$ & 0.421 \\
\hline Median (IQR) & $43(37-73)$ & $40(33-68)$ & \\
\hline \multicolumn{4}{|l|}{ Albumin (g/dL) } \\
\hline Mean \pm SD & $4.08 \pm 0.48$ & $3.9 \pm 0.455$ & 0.000 \\
\hline Median (IQR) & $4(3.7-4.4)$ & $3.9(3.6-4.2)$ & \\
\hline \multicolumn{4}{|c|}{ Prothrombin time $(\mathrm{Sec})$} \\
\hline Mean \pm SD & $13.05 \pm 1.48$ & $12.50 \pm 1.20$ & 0.04 \\
\hline Median (IQR) & $12.9(12-14.5)$ & $12.20(11.30-13)$ & \\
\hline \multicolumn{4}{|c|}{ Total bilirubin $\mathrm{m}(\mathrm{g} / \mathrm{dL})$} \\
\hline Mean \pm SD & $0.69 \pm 0.32$ & $0.61 \pm 0.31$ & 0.004 \\
\hline Median (IQR) & $0.68(0.2-2.20)$ & $0.6(0.2-1.87)$ & \\
\hline \multicolumn{4}{|l|}{ PCR $(\mathrm{IU} / \mathrm{mL})$} \\
\hline Mean \pm SD & $2.16 \pm 2.6 \times 10^{6}$ & $1.98 \pm 2.2 \times 10^{6}$ & \\
\hline Median (IQR) & $\begin{array}{c}9.4 \times 10^{5} \\
\left(2.57 \times 10^{5}-2.68 \times 10^{6}\right)\end{array}$ & $\begin{array}{c}8.22 \times 10^{5} \\
\left(3.02 \times 10^{5}-2.54 \times 10^{6}\right)\end{array}$ & 0.596 \\
\hline \multicolumn{4}{|c|}{$\begin{array}{l}\text { Stage of hepatic fibrosis: } \\
\mathrm{n}(\%) \text { within fibrosis stage }\end{array}$} \\
\hline Fo & 87 (50.9\%) & $84(49.1 \%)$ & \\
\hline F1 & $116(60.7 \%)$ & $75(39.3 \%)$ & 0.037 \\
\hline F2 & $100(57.5 \%)$ & $74(42.5 \%)$ & \\
\hline F3 & $46(67.6 \%)$ & $22(32.4 \%)$ & \\
\hline F4 & $85(49.7 \%)$ & $86(50.35)$ & \\
\hline
\end{tabular}

CHC: Chronic hepatitis C, SD: Standard deviation, IQR: Interquartile range, WBC: White blood cells, ALT: Alanine aminotransferase, AST: Aspartate aminotransferase, PCR: Polymerase chain reaction. 
Table 3. Hematological and biochemical changes after sofosbuvir-based therapy.

\begin{tabular}{cccccccc}
\hline & \multicolumn{2}{c}{ All patients } & \multicolumn{2}{c}{ Males } & \multicolumn{2}{c}{ Females } \\
\cline { 2 - 7 } & Baseline & EOT & EOT-Baseline change & p value & EOT-Baseline change & EOT-Baseline change & p value \\
\hline WBCs & $6.58 \pm 2.30$ & $6.79 \pm 2.09$ & $0.21 \pm 0.07$ & $\mathbf{0 . 0 0 3}$ & $0.12 \pm 0.09$ & $0.34 \pm 0.11$ & 0.276 \\
Hemoglobin & $14.42 \pm 1.69$ & $13.77 \pm 6.94$ & $-0.65 \pm 0.28$ & $\mathbf{0 . 0 1 9}$ & $-1.02 \pm 0.09$ & $-0.21 \pm 0.60$ & 0.626 \\
Platelets & $216.41 \pm 76.23$ & $221.45 \pm 72.12$ & $5.40 \pm 2.07$ & $\mathbf{0 . 0 1 5}$ & $8.23 \pm 3.07$ & $1.21 \pm 2.67$ & $\mathbf{0 . 0 4 9}$ \\
Total bilirubin & $0.65 \pm 0.32$ & $0.80 \pm 0.31$ & $0.15 \pm 0.01$ & $\mathbf{0 . 0 0 0}$ & $0.10 \pm 0.39$ & $0.2 \pm 0.36$ & $\mathbf{0 . 0 0 1}$ \\
Albumin & $3.98 \pm 0.50$ & $3.86 \pm 0.31$ & $-0.11 \pm 0.02$ & $\mathbf{0 . 0 0 0}$ & $-0.05 \pm 0.38$ & $-0.17 \pm 0.48$ & $\mathbf{0 . 0 0 0}$ \\
ALT & $52.76 \pm 36.90$ & $16.73 \pm 7.78$ & $-36.02 \pm 28.12$ & $\mathbf{0 . 0 0 0}$ & $-36.67 \pm 37.98$ & $-35.20 \pm 35.21$ & 0.682 \\
AST & $55.02 \pm 40.08$ & $19.89 \pm 9.26$ & $-35.13 \pm 30.72$ & $\mathbf{0 . 0 0 0}$ & $-34.49 \pm 37.44$ & $-35.96 \pm 42.04$ & 0.815 \\
\hline
\end{tabular}

EOT: End of treatment, WBC: White blood cells, ALT: Alanine aminotransferase, AST: Aspartate aminotransferase.

Table 4. Side effects of DAA therapy in both gender groups.

\begin{tabular}{ccccc}
\hline & Fatigue & Headache & GIT upset & Anemia \\
\hline Sex: Male & $139(32 \%)$ & $82(19 \%)$ & $34(8 \%)$ & $9(2 \%)$ \\
Female & $188(55 \%)$ & $106(31 \%)$ & $116(34 \%)$ & $14(4 \%)$ \\
Total & $327(42 \%)$ & $188(24 \%)$ & $150(16 \%)$ & $23(3 \%)$
\end{tabular}

Chi-square $\chi^{2}=6.17, \mathrm{p}=0.012 \chi^{2}=2.07, \mathrm{p}=0.154 \chi^{2}=15.17, \mathrm{p}=0.000 \chi^{2}=1.62, \mathrm{p}=0.204$ GIT: Gastrointestinal tract.

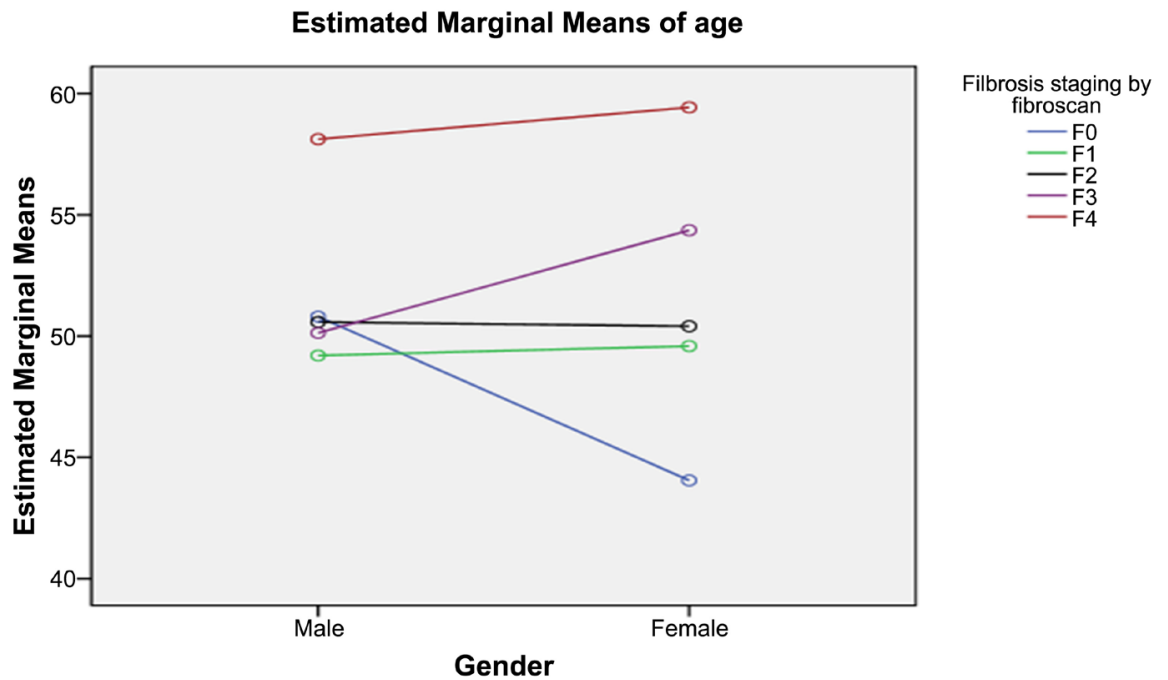

Figure 3. Interaction plots: The effect of patients' mean ages on different stages of hepatic fibrosis $(\mathrm{f}=18.17, \mathrm{p}<0.001)$ and in interaction with patients' gender $(\mathrm{f}=3.04, \mathrm{p}=0.016)$ test by two-way ANOVA.

\section{Gender effect on treatment outcome:}

All patients who received DAA had undetectable virus level at the EOT, but SVR12 was achieved in $98.6 \%$ of them. Females had a better SVR12 than males $(99.4 \%$ versus $97.9 \%)$. Most of the relapsers were males [9 (2.1\%) versus $2(0.6 \%)$ ] (Table 5). 
Table 5. Gender effect on treatment outcome.

\begin{tabular}{llcc}
\hline & & \multicolumn{2}{c}{ Response } \\
\cline { 3 - 4 } & & SVR & Relapse \\
\hline \multirow{2}{*}{ Males } & Count & 425 & 9 \\
& \% within sex & $97.9 \%$ & $2.1 \%$ \\
& $\%$ within responders & $55.6 \%$ & $81.8 \%$ \\
Females Count & 339 & 2 \\
& \% within sex & $99.4 \%$ & $0.6 \%$ \\
& \% within responders & $44.4 \%$ & $18.2 \%$ \\
Total & Count & 764 & 11 \\
& $\%$ within responders & $98.6 \%$ & $1.4 \%$ \\
\hline
\end{tabular}

SVR: Sustained virological response.

\section{Variables predicting relapse of HCV:}

Univariate logistic regression analysis showed that male gender and the presence of advanced hepatic fibrosis and cirrhosis were the significant risk factors associated with relapse of $\mathrm{HCV}$ ( $\mathrm{p}=0.042,0.011$ respectively). However, in multivariate analysis, the only independent predictor of relapse was the presence of advanced hepatic fibrosis and cirrhosis $(\mathrm{p}=0.007)$ (Table 6).

\section{Discussion}

Generally, males and females are different in their health and disease state. This difference could be explained by the difference in exposure to risk factors, sexual hormones, genetic effect and different corporal structures. In addition, CLD may produce different consequences in both genders [13].

In this prospective study which analyzes the characteristics of HCV infection in males compared to females, we found a preponderance of male gender in patients with chronic HCV which was documented by several previous studies [14] [15] [16] [17]. This higher HCV prevalence in males is multifactorial. Males were the main target of parenteral anti-schistosomal therapy campaigns [18]. This may be related to occupational exposure to bilhariziasis during farming. In addition, the possibility of clearance of HCV acute infection is higher in females [9] [19]. Also, there is variance in sex dependent susceptibility to infectious diseases due to the effect of sexual hormones [20] [21]. Estrogens have immune stimulating effect, while androgens have immune suppressing effect resulting in stronger humoral and cellular immune responses to viral infections in females [22]. Similarly, genetic variation had an impact on the outcome of HCV infection. Most immune related genes that determine the response to viral infection are located on X chromosome [13] [23]. In females the activation of X-linked genes related immune cells is greater than males [23], and male patients with chronic HCV carry IL-6 promoter polymorphisms more likely than females [24], while certain polymorphisms in Ctla4, an inhibitory $\mathrm{T}$ cell receptor which is more common in females exposed to infection, are associated with resolution of HCV infection [25]. 
Table 6. Univariate and multivariate analysis of variables predicting relapse of $\mathrm{HCV}$.

\begin{tabular}{|c|c|c|c|c|c|}
\hline \multirow{2}{*}{ Baseline variables } & \multicolumn{2}{|c|}{ Univariate analysis } & \multicolumn{3}{|c|}{ Multivariate analysis } \\
\hline & Odds ratio $(95 \% \mathrm{CI})$ & $\mathrm{p}$ value & Significant variable & Odds ratio $(95 \% \mathrm{CI})$ & $\mathrm{p}$ value \\
\hline Age (years) & $0.98(0.92-1.04)$ & 0.555 & Male versus Female & $3.75(0.82-17.50)$ & 0.09 \\
\hline Sex: Male versus Female & $5.84(1.05-32.41)$ & 0.042 & Stages of fibrosis & $6.32(1.67-24.12)$ & 0.007 \\
\hline BMI & $1.19(0.95-1.26)$ & 0.142 & & & \\
\hline PCR (IU/mL) & $1(1)$ & 0.875 & & & \\
\hline WBCs $\left(\times 10^{3} / \mathrm{mL}\right)$ & $0.89(0.66-1.21)$ & 0.325 & & & \\
\hline Hemoglobin (g/dL) & $1.4(0.68-1.6)$ & 0.613 & & & \\
\hline Platelets count $\left(\times 10^{3} / \mathrm{mL}\right)$ & $1.01(0.99-1.02)$ & 0.465 & & & \\
\hline Total bilirubin (mg/dL) & $0.78(0.11-5.53)$ & 0.713 & & & \\
\hline Serum albumin $(g / d L)$ & $0.33(0.10-1.08)$ & 0.112 & & & \\
\hline Prothrombin time (Sec) & $0.21(0.001-1.01)$ & 0.423 & & & \\
\hline ALT (IU/L) & $0.97(0.94-1.01)$ & 0.222 & & & \\
\hline AST (IU/L) & $1.01(0.98-1.04)$ & 0.563 & & & \\
\hline \multicolumn{6}{|l|}{ Stages of fibrosis: } \\
\hline $\begin{array}{l}\text { - Mild to moderate } \\
\text { - Advanced fibrosis and cirrhosis }\end{array}$ & $5.27(1.20-23.10)$ & 0.011 & & & \\
\hline
\end{tabular}

SVR: Sustained virological response, PCR: Polymerase chain reaction, WBC: White blood cells, ALT: Alanine aminotransferase, AST: Aspartate aminotransferase. 
tests and more progressive fibrosis in males [32]. Poynard et al. reported that males have a twofold greater progression of hepatic fibrosis than females [33]. Several studies documented that progression of HCV infection is worse in males [11] [16]. Also, progression of hepatic fibrosis is reflected in gradual decrease in platelets count [34].

In our study, hepatic fibrosis measured by SWE was significantly more extensive in males than in females. There was significant difference in hepatic fibrosis stages in males compared to females when considering the patients' age. The mean ages of males in different stages of hepatic fibrosis (F0-F3) were closely related, while in females advanced fibrosis (F3) was present in old age. Most of the stages of hepatic fibrosis in females during the reproductive age were mild and moderate fibrosis, while advanced stage of fibrosis was present in old females. Female sex hormones particularly estradiol have important role in limiting hepatic fibrosis progression through their anti-fibrotic properties and inhibition of hepatic stellate cells which are responsible for fibrogenesis beside the protective role against hepatic necroinflammation, apoptosis and oxidative stress [16] [22] [35]. In HCV related CLD and hepatocellular carcinoma the decreased expression of estrogen receptor alfa in males could explain the worse outcome of HCV infection in males [22].

The blood counts were improved apart from mild decrease in hemoglobin level due to the effect of ribavirin, and the liver enzymes were normalized at EOT. Similarly, Ahmed et al. found significant reduction in ALT and AST levels at EOT [36]. Also, we found a slight increase in total bilirubin level, decrease in serum albumin level and appearance of some clinical side effects (fatigue and GIT upset) after initiation of DAA therapy which were significantly more in females. Similar to our results, the most recorded adverse events of DAA in several previous studies were fatigue, headache, nausea and diarrhea [36] [37]. Generally, females experienced greater adverse events to antiviral drugs than males [38] [39]. In contrast, Attia et al. reported that male gender was significantly associated with the occurrence of adverse events to DAA therapy as anemia and hyperbilirubinemia [40].

Since introduction of DAA therapy the outcome of chronic HCV infection was markedly improved [36]. The efficacy and safety of sofosduvir based DAA regimens have been proven in several Egyptian studies, and the combination of sofosbuvir/daclatasvir with and without ribavirin showed high SVR rates between $92 \%$ and 98.9\% [12] [41] [42]. However, the gender effect on the potential efficacy and safety of DAA therapy is not sufficiently studied.

In our study, all patients who received DAA therapy had undetectable virus level at the EOT. SVR12 was achieved in $98.6 \%$ of all studied patients; although females had a better SVR12 than males and most of the relapsers were males, this difference is not clinically relevant. Similarly, some studies found that female sex and less hepatic fibrosis were independently associated with higher rates of SVR. Also, fertile women with genotypes 2 or 3 have a better response to 
therapy [43] [44] [45] [46]. However, these studies were on interferon-based therapy. On the other hand, Yang et al. found that SVR was high in patients treated with DAA therapy regardless of age, gender or hepatic fibrosis stage [47].

In univariate analysis we found that male gender and the presence of advanced hepatic fibrosis and cirrhosis were significant predictors of relapse after DAA therapy. While in multivariate analysis we found that the only independent predictor of relapse was the presence of advanced hepatic fibrosis and cirrhosis, but still male patients have 3.75 times more risk to relapse than females.

\section{Conclusion and Recommendation}

Males were different from females in exposure to HCV risk factors. After introduction of blood screening and stoppage of parenteral anti-bilharzial therapy the risk of $\mathrm{HCV}$ infection could be greatly prevented in males. On the other hand, the exposure of females to obstetric procedures is increasing nowadays which hide a risk of ongoing infection in females. So, HCV surveillance programs in females retain their importance in early detection and management of $\mathrm{CHC}$. $\mathrm{Al}$ though hepatic fibrosis progression was more in males, females were more liable to adverse events of DAA therapy than males. So, researchers should consider the gender of their patients in drug design and administration.

\section{Conflicts of Interest}

The authors declare no conflicts of interest regarding the publication of this paper.

\section{References}

[1] World Health Organization (WHO) (2016) Hepatitis C Fact Sheet.

[2] Blach, S., Zeuzem, S., Manns, M., et al. (2016) Global Prevalence and Genotype Distribution of Hepatitis C Virus Infection in 2015: A Modelling Study. The Lancet Gastroenterology and Hepatology, 2, 161-176. https://doi.org/10.1016/S2468-1253(16)30181-9

[3] Gomaa, A., Allam, N., Elsharkway, A., et al. (2017) Hepatitis C Infection in Egypt: Prevalence, Impact and Management Strategies. Hepatic Medicine: Evidence and Research, 9, 17-25. https://doi.org/10.2147/HMER.S113681

[4] Kandeel, A., Genedy, M., El-Refai, S., et al. (2017) The Prevalence of HCV Infection in Egypt 2015: Implications for Future Policy on Prevention and Treatment. Liver International, 37, 45-53. https://doi.org/10.1111/liv.13186

[5] Medhat, A., Shehata, M., Magder, L.S., et al. (2002) Hepatitis C in a Community in Upper Egypt: Risk Factors for Infection. The American Journal of Tropical Medicine and Hygiene, 66, 633-638. https://doi.org/10.4269/ajtmh.2002.66.633

[6] Williams, I. (1999) Epidemiology of Hepatitis C in the United States. The American Journal of Medicine, 107, 2S-9S

[7] Wasley, A. and Alter, M.J. (2000) Epidemiology of Hepatitis C: Geographic Differences and Temporal Trends. Seminars in Liver Disease, 20, 1-16.

https://doi.org/10.1055/s-2000-9506

[8] Ayoub, H.H. and Abu-Raddad, L.J. (2016) Impact of Treatment on Hepatitis C Vi- 
rus Transmission and Incidence in Egypt: A Case for Treatment as Prevention. Journal of Viral Hepatitis, 31, 1267.

[9] Bakr, I., Rekacewicz, C., El Hosseiny, M., et al. (2006) Higher Clearance of Hepatitis C Virus Infection in Females Compared with Males. Gut, 55, 1183-1187. https://doi.org/10.1136/gut.2005.078147

[10] Guy, J. and Peters, M.G. (2013) Liver Disease in Women: The Influence of Gender on Epidemiology, Natural History, and Patient Outcomes. Gastroenterology \& Hepatology, 9, 633-639.

[11] Seeff, L.B. (2002) Natural History of Chronic Hepatitis C. Hepatology, 36, S35-S46. https://doi.org/10.1053/jhep.2002.36806

[12] Abdel-Moneim, A., Aboud, A., Abdel-Gabaar, M., et al. (2018) Efficacy and Safety of Sofosbuvir plus Daclatasvir with or without Ribavirin: Large Real-Life Results of Patients with Chronic Hepatitis C Genotype 4. Hepatology International, 12, 348-355. https://doi.org/10.1007/s12072-018-9868-8

[13] Durazzo, M., Belci, P., Collo, A., et al. (2014) Gender Specific Medicine in Liver Diseases: A Point of View. World Journal of Gastroenterology, 20, 2127-2135.

https://doi.org/10.3748/wjg.v20.i9.2127

[14] Naga, M., Esmat, S., Ahmed, H., et al. (2019) Clinical Characteristics of HCV in Egyptian Patients. EC Gastroenterology and Digestive System, 6, 168-179.

[15] Al-Zanaty, F. (2015) Egypt Demographic and Health Survey 2014. Ministry of Health and Population, Cairo.

[16] Bissell, D.M. (1999) Sex and Hepatic Fibrosis. Hepatology, 29, 988-989. https://doi.org/10.1002/hep.510290351

[17] Naugler, W.E., Sakurai, T., Kim, S., et al. (2007) Gender Disparity in Liver Cancer Due to Sex Differences in MyD88-Dependent IL-6 Production. Science, 317, 121-124. https://doi.org/10.1126/science.1140485

[18] Frank, C., Mohamed, M.K., Stricland, G.T., et al. (2000) The Role of Parenteral Anti-Schistosomal Therapy in the Spread of Hepatitis C Virus in Egypt. The Lancet, 355, 887-891. https://doi.org/10.1016/S0140-6736(99)06527-7

[19] Yamakawa, Y., Sata, M., Suzuki, H., et al. (1996) Higher Elimination Rate of Hepatitis C Virus among Women. Journal of Viral Hepatitis, 3, 317-321. https://doi.org/10.1111/j.1365-2893.1996.tb00104.x

[20] Klein, S.L. (2000) The Effects of Hormones on Sex Differences in Infection: From Genes to Behavior. Neuroscience \& Biobehavioral Reviews, 24, 627-638. https://doi.org/10.1016/S0149-7634(00)00027-0

[21] Knapp, S., Yee, L.J., Frodsham, A.J., et al. (2003) Polymorphisms in Interferon-Induced Genses and the Outcome of Hepatitis C Virus Infection: Roles of MxA, OAS-1 and PKR. Genes and Immunity, 4, 411-419. https://doi.org/10.1038/sj.gene.6363984

[22] Ruggieri, A., Gagliardi, M.C. and Anticoli, S. (2018) Sex-Dependent Outcome of Hepatitis B and C Viruses Infections: Synergy of Sex Hormones and Immune Responses? Frontiers in Immunology, 9, 2302-2319. https://doi.org/10.3389/fimmu.2018.02302

[23] Stamova, B., Tian, Y., Jickling, G., et al. (2011) The X-Chromosome Has a Different Pattern of Gene Expression in Women Compared with Men with Ischemic Stroke. Stroke, 43, 326-334.

[24] Cussigh, A., Falleti, E., Fabris, C., et al. (2011) Interleukin 6 Promoter Polymorphisms Influence the Outcome of Chronic Hepatitis C. Immunogenetics, 63, 33-41. 
https://doi.org/10.1007/s00251-010-0491-7

[25] Schott, E., Witt, H., Hinrichsen, H., et al. (2007) Gender-Dependent Association of CTLA4 Polymorphisms with Resolution of Hepatitis C Virus Infection. Journal of Hepatology, 46, 372-380. https://doi.org/10.1016/j.jhep.2006.09.011

[26] Al-Balbissi, A.H. (2003) Role of Gender in Road Accidents. Traffic Injury Prevention, 4, 64-73. https://doi.org/10.1080/15389580309857

[27] McCrum, M.L., Leroux, B., Fang, T., et al. (2019) Sex-Based Differences in Transfusion Need after Severe Injury: Findings of the PROPPR Study. Surgery, 165, 1122-1127. https://doi.org/10.1016/j.surg.2018.12.023

[28] Arafa, N., El Hoseiny, M., Rekacewicz, C., et al. (2005) Changing Pattern of HCV Spread in Rural Areas of Egypt. Journal of Hepatology, 43, 418-424. https://doi.org/10.1016/j.jhep.2005.03.021

[29] Murphy, W.G. (2014) The Sex Difference in Haemoglobin Levels in Adults-Mechanisms, Causes, and Consequences. Blood Reviews, 28, 41-47.

https://doi.org/10.1016/j.blre.2013.12.003

[30] Kallner, A., Gustavsson, E. and Hendig, E. (2000) Can Age and Sex Related Reference Intervals Be Derived for Non-Healthy and Non-Diseased Individuals from Results of Measurements in Primary Health Care? Clinical Chemistry and Laboratory Medicine, 38, 633-654. https://doi.org/10.1515/CCLM.2000.093

[31] Weaving, G., Batstone, G.F. and Jones, R.G. (2016) Age and Sex Variation in Serum Albumin Concentration: An Observational Study. Annals of Clinical Biochemistry, 53, 106-111. https://doi.org/10.1177/0004563215593561

[32] Narciso-Schiavon, J.L., Schiavon, L.L., Carvalho-Filho, R.J., et al. (2008) Anti-Hepatitis C Virus-Positive Blood Donors: Are Women Any Different? Transfusion Medicine, 18, 175-183. https://doi.org/10.1111/j.1365-3148.2008.00859.x

[33] Poynard, T., Bedossa, P., Opolon, P., et al. (1997) Natural History of Liver Fibrosis Progression in Patients with Chronic Hepatitis C. The OBSVIRC, METAVIR, CLINIVIR, and DOSVIRC Groups. The Lancet, 349, 825-832. https://doi.org/10.1016/S0140-6736(96)07642-8

[34] Bataller, R. and Brenner, D.A. (2005) Liver Fibrosis. Journal of Clinical Investigation, 115, 209-218. https://doi.org/10.1172/JCI24282

[35] Di Martino, V., Lebray, P., Myers, R.P., et al. (2004) Progression of Liver Fibrosis in Women Infected with Hepatitis C: Long-Term Benefit of Estrogen Exposure. $\mathrm{He}-$ patology, 40, 1426-1433. https://doi.org/10.1002/hep.20463

[36] Ahmed, O.A., Safwat, E., Khalifa, M.O., et al. (2018) Sofosbuvir plus Daclatasvir in Treatment of Chronic Hepatitis C Genotype 4 Infection in a Cohort of Egyptian Patients: An Experiment the Size of Egyptian Village. International Journal of Hepatology, 2018, Article ID: 9616234. https://doi.org/10.1155/2018/9616234

[37] Babatin, M.A., Alghamdi, A.S., Albenmousa, A., et al. (2017) Efficacy and Safety of Simeprevir or Daclatasvir in Combination with Sofosbuvir for the Treatment of Hepatitis C Genotype 4 Infection. Journal of Clinical Gastroenterology, 2017, Article ID: 28767462. https://doi.org/10.1097/MCG.0000000000000896

[38] Soldin, O.P. and Mattison, D.R. (2009) Sex Differences in Pharmacokinetics and Pharmacodynamics. Clinical Pharmacokinetics, 48, 143-157. https://doi.org/10.2165/00003088-200948030-00001

[39] Klein, S.L. (2012) Sex Influences Immune Responses to Viruses, and Efficacy of Prophylaxis and Therapeutic Treatments for Viral Diseases. Bioessays, 34, 1050-1059. https://doi.org/10.1002/bies.201200099 
[40] Attia, D., El Saeed, K., Elakel, W., et al. (2018) The Adverse Effects of Interferon-Free Regimens in 149816 Chronic Hepatitis C Treated Egyptian Patients. Alimentary Pharmacology \& Therapeutics, 47, 1296-1305. https://doi.org/10.1111/apt.14538

[41] El Kassas, M., Omran, D., Elsaeed, K., et al. (2018) Spur-of-the-Moment Modification in National Treatment Policies Leads to a Surprising HCV Viral Suppression in All Treated Patients: Real-Life Egyptian Experience. Journal of Interferon \& Cytokine Research, 38, 81-85. https://doi.org/10.1089/jir.2017.0121

[42] Omar, H., El Akel, W., Elbaz, T., et al. (2018) Generic Daclatasvir plus Sofosbuvir, with or without Ribavirin, in Treatment of Chronic Hepatitis C: Real-World Results from 18378 Patients in Egypt. Alimentary Pharmacology \& Therapeutics, 47, 421-431. https://doi.org/10.1111/apt.14428

[43] Roberts, S.S., Miller, R.K., Jones, J.K., et al. (2010) The Ribavirin Pregnancy Registry: Findings after 5 Years of Enrollment, 2003-2009. Birth Defects Research Part A: Clinical and Molecular Teratology, 88, 551-559. https://doi.org/10.1002/bdra.20682

[44] Floreani, A., Cazzagon, N., Boemo, D.G., et al. (2011) Female Patients in Fertile Age with Chronic Hepatitis C, Easy Genotype, and Persistently Normal Transaminases Have a $100 \%$ Chance to Reach a Sustained Virological Response. European Journal of Gastroenterology \& Hepatology, 23, 997-1003. https://doi.org/10.1097/MEG.0b013e32834ae863

[45] McHutchison, J.G., Lawitz, E.J., Shiffman, M.L., et al. (2009) Peginterferon alfa-2b or alfa-2a with Ribavirin for Treatment of Hepatitis C Infection. The New England Journal of Medicine, 361, 580-593. https://doi.org/10.1056/NEJMoa0808010

[46] Conjeevaram, H.S., Fried, M.W., Jeffers, L.J., et al. (2006) Peginterferon and Ribavirin Treatment in African American and Caucasian American Patients with Hepatitis C Genotype 1. Gastroenterology, 131, 470-477. https://doi.org/10.1053/j.gastro.2006.06.008

[47] Yang, Y., Wu, F.P., Shi, J.J., et al. (2019) Real Life Efficacy and Safety of Direct-Acting Antiviral Therapy for Treatment of Patients Infected with Hepatitis $\mathrm{C}$ Virus Genotypes 1, 2 and 3 in Northwest China. World Journal of Gastroenterolo$g y$, 25, 6551-6560. https://doi.org/10.3748/wjg.v25.i44.6551 